\title{
Preface: Why Filipinos?
}

"Pilipino ka ba?" I never know what to say when I hear these words. Am I Filipino? "Um-yes, I am," I answered. "Ah-Kano, ha?" he said, confirming his suspicion that I'm an American. Okay, maybe I'm not a Filipino. ... I always feel awkward whenever an older, first generation Filipino American asks me about my ethnicity. I never know what to say.

- Journal entry, November 1995

"Good-your mama raised you as a Filipino. My other niece shook my hand when she greeted me. That's [shaking one's hand] very American. And to think she was raised here in the Philippines! Cora-you raised Emily right!" -Journal entry, June 1991, written during trip to the Philippines

I never understood what it meant to be Filipino. As I was growing up, I received so many conflicting definitions that by the time I reached high school I was sure that no one (not even my parents, who are firstgeneration immigrants) could sit down and tell me what it means. At first, I'd thought that, perhaps, this phenomenon was unique to my family. I'd grown up in what is often called an "extended family household"; that is, I lived in a house filled with aunts, uncles, grandparents, cousins, my mom and dad, and even, at one point, seven dogs and a turtle named Floppy. To many of my classmates, colleagues, and many others I have encountered throughout my life, this may seem like an extraordinary case. Yet, to many racial minority groups and immigrants of all races, especially within the United States, this is what we consider to be "family" (hooks 1994; Stacks 1996). At any rate, I 
attributed my confusion over what constitutes a "true" Filipino to my experience of living with several self-defined Filipinos who each had different ideas of what it means to be "Pinoy."1

But, as I met more Filipino Americans, particularly my students while I was a graduate student-teacher at the University of Illinois, I realized that my dilemma was not unique to my family. Indeed, the popularity of the grassroots film The Debut $(2002)^{2}$ is evidence that questions of identity among Filipinos are just as commonplace as with other races and/or ethnicities. Yet finding a singular, authentic Filipino identity is important to many Filipino Americans. Espiritu (1994) found that Filipino Americans feel as if they aren't completely regarded as Americans by their non-Filipino counterparts because of their racial characteristics. In other words, like other racially subjugated and racialized ethnic groups, Filipino Americans' brown skin and/or other physical characteristics, such as eye shape, hair color, and nose shape, preclude their ability to be recognized as "real" Americans. This project stems from understanding the importance of discovering and being able to articulate a singular sense of Filipino; but as a Filipino Canadian who grew up in the United States and as a sociologist, I know that finding a singular identity is akin to acquiring the Holy Grail.

Most Filipino Americans acknowledge diverse, sometimes contradictory definitions of Filipino (Bonus 1997, 2000; Espiritu 1995; Manalansan 1995). While some celebrate this diversity, some believe it is a weakness. The latter group believes that we lack a unifying definition because of our ignorance, erasure, or even rejection of authentic culture. This belief is most probably prevalent because scholars have erroneously described Filipinos as a "people without culture" because they had spent "three hundred years in a monastery [under Spanish colonial rule] and a half century in Hollywood [under American colonial rule]" (Rosaldo 1989, 77). Because many cultures in the Philippines seem to have embraced American culture, they have somehow lost any claims of authenticity; ${ }^{3}$ hence, the Philippines and Filipino culture have not been studied as extensively as other cultures. This institutional erasure has not only devalued Filipino culture, it has made Filipinos feel somewhat invisible. Or worse, any problems or social issues we claim affect us are not "real." Yet, the Philippines and Filipinos are at the center of a very real history of colonialism and economic exploitation which still profoundly affect Filipinos all over the world and place us squarely within U.S. history and corresponding histories of resistance. 
This presumed nonexistence of an authentic Filipino culture profoundly affects Filipinos outside academia. Many debates on soc. culture.filipino, the Internet newsgroup I studied, reflect most participants' goal of eradicating Filipinos' colonial mentality and teaching all Filipinos to learn about their "real" culture. Many of the participants argue that Filipinos can make themselves more visible through learning about culture. But achieving this goal is difficult because participants disagree on the description of Filipino culture. Some celebrate the different influences (such as Chinese, Spanish, Japanese, and American) that have shaped the Philippines and Filipinos: "You know, there are no 'real' Filipinos. We're all mixed up. And all those different cultures mixed together is what makes us unique." Others are more critical because they have seen Filipinos "embracing the influences and rejecting [their] culture. Filipinos are so Americanized now. They don't know their culture and they reject anything that's Filipino.” Some participants remain confused about Filipino culture and identity and are doubtful whether Filipinos can ever achieve political visibility because of the apparent lack of a static, solid, homogenous culture. These sentiments are echoed by many ethnic, racial, and immigrant groups within the United States about their own cultures.

Similarly, many second-generation Filipino Americans have stated that to find information about our culture and identity, it is "best to go to the source"- to first-generation Filipino Americans or, better yet, to Filipinos who reside in the Philippines. This desire has led many of my students through the years to the Internet, specifically to the soc.culture.filipino newsgroup. This turn to the Internet for knowledge is what led me to this study.

No matter how large the network of aunts, uncles, lolos, lolas, ${ }^{4}$ and godparents my students and I belonged to, the prospect of talking with twenty thousand or more Filipinos from all over the world was appealing in that we were able to "test" our ideas of what constitutes Filipino on people we had not actually met, but with whom we still felt a sense of kinship. The Internet is a medium in which people can be both intimately involved and anonymous; people in the newsgroup may get to know one another through their posts (and the tone of their posts), yet they may never actually see one another. In many ways, it is easier to post a question on the Internet than face a gaggle of aunts and uncles whose boisterous laughter could send an already timid second (or more) removed generation Filipino American further into the nebula of the Margins. Thus, on the surface, it appears that 
the Internet would help second- and later-generation Filipino Americans (as well as other diasporic Filipinos) efficiently and quickly obtain information about Filipino culture and identity from "the source," as "traveling" to and "talking" with "real" Filipinos from the homeland could be done more easily online than via traditional traveling methods.

\section{Diary of a Cyborg: Reflections on Analysis}

White, First World authors who are interested in studying works from Third World cultures are often told that they "can't understand other cultures until [they] understand their own" (Lippard 1990). On the flip side, because I am a Filipino American who grew up in an extended family household of first generation immigrants and “1.5ers” (i.e., people who immigrated at a young age), non-Filipino colleagues often assume that I have a complete understanding of both Filipino and American cultures and, therefore, can "look from the outside in and from the inside out" (hooks 1994).

However, the process of collecting and analyzing empirical material for this project has reinforced my feelings that I can neither look from the outside in nor from the inside out. Rather, I see things from a liminal space, neither Filipino nor American, but a unique combination of both. In addition, other factors have influenced the way we all understand the world: my race, citizenship (I am Canadian), gender, accent, as well as my physical appearance and my last name have all contributed to my experiences and given me a unique perspective.

For example, two weeks after I arrived as a graduate student in the sociology department at the University of Illinois, a woman approached me and said, "Okay, Em. Grace ${ }^{5}$ and I have a bet here. I think you're Latino. She thinks you're Asian. So which one are you?” Having heard many variations of this question before, I gave them my standard answer: "I'm Canadian," I said as I walked away. Instead of playing the race game, I have chosen since grade school to annoy people by telling them about my citizenship rather than my race.

When I was younger, I used to answer "both" when asked if I was Asian or Latino because one of my grandmothers is Chinese and one of my grandfathers is Spanish. However, this conversation would often take too long, because being "mixed" warranted some explanation. When asked about my "mixed race," I couldn't give them an entire history lesson, although this was often what my curious peers wanted. 
I didn't know anything about colonization when I was a kid, but my parents had explained their different ethnicities by telling me that the Spaniards, Chinese, and Malays visited the Philippines, liked it, and decided to stay. So, I opted for the shorter, pithier answer. "I'm Canadian (or worse, "I'm a Chicagoan”). What are you?"

Other Filipino Americans also have their own perspectives. For example, my cousin, a 1.5-generation immigrant with whom I grew up, assures me that she can look from the outside in and from the inside out. Because she was born in the Philippines and immigrated here when she was ten, she has the experience of living and studying in the Philippines as well as the United States. For the first few years in the United States, she had to assure our family that she was still Filipino while assuring her non-Filipino classmates that she knew how to be American. As a result, she vacillated back and forth on a daily, sometimes hourly basis, proving herself to both camps. While I was somewhat comfortable maneuvering in the nether areas, her struggles with our family and with non-Filipino classmates, as well as her marriage to a later generation Italian American, taught her, she argues, how to be both an American and a Filipino. Yet, she also tells me of her constant efforts to prove herself as either and both.

Although we grew up in the same small neighborhood, lived in the same household, and went to the same schools, what struck me most is the difference between our experiences and the outcomes. My "extended" family could never perceive me as a true Filipino, despite the fact that they taught me to understand both Filipino dialects spoken at home, despite the fact that I learned and followed the customs they taught me, and despite my attempts to learn about the Philippines and the culture. Never mind that until I went to college, they were more versed in American history and politics than I was or that when they immigrated here, they already knew and practiced many American customs. My being born and raised outside the Philippines, according to my family, is the determining factor for my ethnic identity. Like my cousins who were born and/or largely raised in the United States, my family continues to distinguish between their "Filipinoness" and my lack of it. Thus, my effort to learn about Filipinos and the Philippines is akin to a subject that I'm interested in, while for others it is "catching up with what's going on at home."

Yet, when relatives visited from the Philippines, they always commented on how "Americanized" my extended family had become while simultaneously praising my family for raising me as a "true Filipino." 
And outside my home, in my classmates and teachers' eyes, I was the resident Filipino, often asked to translate words into Tagalog or to explain certain customs. They did not doubt that I was Filipino, even though I demonstrated through social interactions and academic ventures that I clearly understood the American way of life.

I have struggled with these issues since many members of my family immigrated to the United States, and I have recently concluded that all of them are right: I cannot be Filipino as they are Filipino, just as there is no one way to be white, black, Asian, Latino, Native American, Chinese, Ethiopian, Lakota, or other races or ethnicities. ${ }^{6}$ This does not mean that I have no ethnic identity, nor do I consider myself a wandering, marginal person. Although some members of my family do not regard me as an authentic Filipino, I perceive this not as a rejection (although it is trying sometimes), but as an opportunity to question why they and others (especially second-generation Filipino Americans) believe there is only one way to be Filipino, as it has been so clear, even within our home, that there are several ways to be Filipino.

Because I have heard my family continually discuss whether I or other Filipino Americans are Filipino, I have sensed the fluidity of culture and identity as well as cultural syncretism and heterogeneity within the Filipino community for most of my life.

No need to hear your voice when I can talk about you better than you can speak about yourself. No need to hear your voice. Only tell me about your pain. I want to know your story. And then I will tell it back to you in a new way. Tell it back to you in such a way that it has become mine, my own. Re-writing you I write myself anew. I am still author, authority. I am still colonizer, the speaking subject and you are now at the center of my talk. (bell hooks 1994, 343)

My biggest fear in doing this project was that I would suppress instead of support the voices of Filipinos on the newsgroup. Even though I use each participant's own words, I know that the analysis of these words is mine; thus, "I am still author, authority."

Yet, I was an active participant on the newsgroup and a FilipinoAmerican struggling with issues of identity. Although I did not post very often, I did follow each discussion very carefully for over two 
years. When I needed clarification (depending on the touchiness of the question), I posted an e-mail to the whole group or e-mailed the person privately. If the posts concerned the contents of a Web page, I logged onto the Web and studied the page in question. Some threads lasted over a month, others only a few days. And I was there, an active participant and a researcher in this newsgroup. That said, I extend my hand and welcome you to my virtual home of two years. 

Building Diaspora 
